\title{
Projovem :o desafio do protagonismo juvenil em unidades de medida socioeducativa feminina e masculina
}

\section{Projovem: the challenge of youth protagonism in female and male juvenile detention centers}

DOI: $10.46814 /$ lajdv3n3-008

Recebimento dos originais: 23/12/2020

Aceitação para publicação: 26/02/2021

\section{Danubia Capucho Teixeira}

Universidade Estácio de Sá.

E-mail: danubiacapucho@globomail.com

\author{
Carolina Monteiro \\ Instituto Federal de Educação, Ciências e Tecnologia do Rio de Janeiro. E-mail: \\ carolinagfm@yahoo.com.br \\ Ester Rebeca Filipini \\ Instituto Universidade Federal do Rio de Janeiro. \\ E-mail: esterfilipini@gmail.com \\ Jessica Ribeiro de Castro \\ Universidade Federal do Rio de Janeiro. \\ E-mail: jessicaa_ribeiro@hotmail.com \\ Janaína Dória Líbano Soares \\ Instituto Federal de Educação, Ciências e Tecnologia do Rio de Janeiro. \\ E-mail: janaina.soares@ifrj.edu.br \\ Rafaela Mendes Soares \\ Universidade Federal do Rio de Janeiro. \\ E-mail: rafaela_mendess@live.com
}

\section{RESUMO}

A adolescência é um período de transição, permeada por conflitos, onde o jovem começa a se responsabilizar por seus atos, podendo estar vulnerável a cometer atos infracionais.

As adolescentes em conflito com a lei do Estado do Rio de Janeiro, em cumprimento de internação, são levadas ao Centro de Socioeducação Dom Bosco (unidade feminina) e Escola João Luiz Alves (unidade masculina) do Departamento Geral de Ações Socioeducativas (DEGASE), órgão responsável em promover medidas socioeducativas, indicado pelo Estatuto da Criança e do Adolescente (ECA). Este projeto tem como objetivo o protagonismo juvenil, promoção da saúde e direitos humanos, como uma ferramenta para auxiliar as adolescentes a fazerem escolhas mais saudáveis e serem mais autônomas em suas vidas.

Palavras Chave: protagonismo, promoção de saúde, vulnerabilidade, jovens, ato infracional, medida socioeducativa. 


\section{INTRODUÇÃO}

Segundo o Estatuto da Criança e do Adolescente (ECA) são penalmente inimputáveis os menores de dezoito anos que cometem crime ou contravenção penal. A estes jovens são perpetradas medidas sócio-educativas. Em seu artigo $112^{\circ}$, o ECA descreve as possíveis medidas as quais o órgão competente pode aplicar ao adolescente após verificada a prática do ato infracional. Entre elas está a medida de internação, que é descrita como aquela que coloca o infrator sob custódia do Estado, privando-o de liberdade total ou parcial.

Os conceitos de risco e vulnerabilidade são conceitos distintos, mas intrinsecamente relacionados, pois, enquanto risco refere-se às condições fragilizadas da sociedade num todo, a vulnerabilidade identifica as condições dos indivíduos e suas suscetibilidades à respostas e/ou consequências negativas (Oliveira, 1995). É neste contexto que estão inscritos os adolescentes que praticam atos infracionais e cumprem medidas socioeducativas.

Oliveira (1995) afirma que a vulnerabilidade dos grupos sociais somente será superada quando se transitar a noção de carências sociais para o terreno de direitos sociais. Direitos e cidadania são conceitos que implicam na promoção de habilidades dos indivíduos e da coletividade em compreender, analisar, refletir e se conscientizar sobre a realidade, tornando-se assim, um cidadão participativo, gerando desenvolvimento pessoal e social.

Neste âmbito, o PROJOVEM visa estimular o protagonismo juvenil para que adolescentes em conflito com a lei que cumprem medidas socioeducativas sejam capazes de adquirir uma maior competência e segurança na autogestão de suas vidas. Por tanto, o projeto tem como campo de intervenção social o enfrentamento das questões relacionadas aos adolescentes em conflito com a lei e a possibilidade de redução da reincidência do ato infracional, através da promoção de saúde, utilizando o protagonismo juvenil como estratégia central, entendendo este é o ato do adolescente ser o principal responsável no seu processo de desenvolvimento.

O PROJOVEM consiste, então, em uma proposta integrada de promoção de saúde e direitos humanos que visa a inclusão social de adolescentes que cumprem medida socioeducativa. Tendo em vista que os riscos e as vulnerabilidades sociais emergem de diferentes fatores interdependentes, estratégias para reduzi-los e ampliar a inclusão requerem ações em várias frentes. Por isto, se faz a necessária discussão da relação entre saúde e direitos humanos, exigindo o planejamento para que elas sejam executadas de forma integrada e complementar.

O presente projeto tem como objetivo central promover o protagonismo juvenil na saúde destes jovens para que estes mudem seus hábitos e comportamentos, levando-os assim a fazerem escolhas mais saudáveis, tendo uma maior competência e segurança na autogestão de suas vidas. 


\section{APRESENTAÇÃO DA TEMÁTICA}

Nesse cenário socioeducativo atua o Programa de Extensão "Protagonismo Juvenil como estratégia de promoção de saúde em situação de risco e vulnerabilidade biopsicossocial" (PROJOVEM). O projeto, iniciado em abril de 2013 e encontra-se em andamento até a presente data (Maio/2015), está vinculado ao Instituto Federal de Educação, Ciências e Tecnologias do Rio de Janeiro - Campus Realengo. As atividades são desenvolvidas por uma equipe multidisciplinar em duas unidades do Departamento Geral de Ações Socioeducativas: Escola João Luiz Alves (Unidade Masculina) e Centro de Socioeducação Dom Bosco (Unidade Feminina). Participaram das atividades ao longo deste tempo cerca de 52 meninas entre 12 e 19 anos. E na unidade masculina cerca de 63 meninos entre 14 e 18 anos.

A metodologia utilizada com os adolescentes é participativa e considera o protagonismo dos jovens, atrelado a informação e a realidade das adolescentes. Propõem-se atividades que desenvolvem a criatividade, o trabalho em equipe, a crítica e intervenção na realidade através de temas sugeridos pelos adolescentes ou por demandas observadas ao término dos encontros.

Foram abordados os temas Noções de saúde, respeito, educação, preconceito, sexualidade, drogas, as novas constelações familiares, redução da maioridade penal, feminicídio, empoderamento, autoestima, entre diversos temas trazidos por eles com questões a serem discutidas. No encontro sobre Noções de Saúde, os adolescentes demonstraram ter noção do que é saudável ou não, além da importância de se ter hábitos saudáveis, mas confessaram que nem sempre os têm por diversos motivos,mas demonstram a vontade de ter essas condições mais favoráveis à própria saúde.

Houve cerca de três encontros sobre o tema Respeito e Educação. Os adolescentes mostraram como é difícil para eles respeitarem e ainda disseram só respeitar quem os respeita, apesar de assumirem o quanto é importante o respeito para a convivência entre eles e no meio onde vivem. E como a falta de educação os leva a ter menos acesso a tudo que se vincula ao meio social.

Foram dois encontros sobre Preconceito. Os pesquisadores tiveram a oportunidade de perceber através do protagonismo dos jovens as percepções e vivências sobre preconceito linguístico, social, racial e opção ou condição sexual do outro( muito discutido no tema das novas constelações familiares).

Nos encontros sobre Sexualidade, eles apresentaram as dúvidas tanto quanto ao exercício da sexualidade como a respeito dos métodos contraceptivos, assim como dúvidas sobre a maternidade/paternidade, já que muitas adolescentes já são mães e na unidade dos meninos a maioria já era pai.Alguns adolescentes viram uma camisinha pela primeira vez ( levamos a feminina e a masculina para que pudessem visualizar).

Houve alguns encontros com o tema Drogas. Nestes, as meninas se declararam dependentes químicas, outras falaram dos dramas familiares em decorrência do uso e venda das drogas. Falou-se 
sobre comércio e consumo de drogas lícitas e ilícitas. Na unidade masculina foi citada com certa angústia, a necessidade de "entrar para o tráfico" desde muito cedo por conta da condição social e falta de preparo, relatando com tristeza o fato e sinalizando a falta de oportunidades e a vontade de mudar, e alguns relataram que faziam uso apenas para estar inserido no grupo... Foi um tema que gerou reflexões importantes.

Sobre as novas constelações familiares, fluiu melhor na unidade feminina, ao qual conseguem visualizar com maior clareza a mudança que ocorre através do tempo.Já os meninos tiveram uma atitude mais engessada e não concordam muito com as formações familiares que divergem as antigas tradicionais.Com algumas falas "antigas" e colocadas em cunho religioso onde "Deus fez o homem e a mulher"...

A Redução da Maioridade Penal, foi tema unânime entre os grupos,que se descreveram como sendo a parte prejudicada,comentaram sobre a falta de interesse dos governantes em tentar ajudá-los de forma precisa e com mínimo de dignidade.Os encontros falados sobre feminicidio e empoderamento ( os mais recentes) Também divergiram opiniões entre o grupos,já que os meninos foram “construídos “ com uma cultura mais machista,acham que a mulher hoje em dia não se dá o devido respeito e acaba que o homem precisa se impor, para que não perca o respeito entre seu círculo de convivência.E a violência acaba sendo uma "conseqüência natural",nesses casos sempre tentamos colocar que jamais a violência resolverá algumas coisa,ou ajudará no conflito,porém na parte dos meninos,houve certa resistência,contudo sempre nos ouvindo e conversando com respeito.

Percebemos que em determinadas épocas, a "masculinização" das meninas que se apresentavam de cabelos bem curtos, usavam tops que apertavam bem os seios, que quase não os era percebido, e elas quando questionadas sobre a vaidade ou autoestima, relatavam que este "disfarce", servia para sua própria proteção, seja nas ruas,onde sempre sofrem abusos e violência, ou dentro da instituição por outras adolescentes.

É possível afirmar que o diálogo possibilita estreitamento da relação com as adolescentes e favorece o alcance dos objetivos do projeto. As ações despertam interesse dos adolescentes e contribuem para a transformação almejada.

O PROJOVEM leva à contestação da realidade dos adolescentes em conflito com a lei e a de toda a sociedade, permitindo uma análise societária crítica que excede o empirismo, atingindo uma discussão mais ampla, sem pré-julgamentos ou preconceitos. O protagonismo desejado é capaz de transformar as condições objetivas e subjetivas dos adolescentes e de permitir a transformação na maneira em que estão inseridas nas expressões de saúde e direitos humanos. O cronograma do projeto foi dividido em algumas etapas que abordam questões relativas a saúde; abordam a noção dos direitos segundo o Estatuto da Criança e do Adolescente numa perspectiva 
pessoal dos adolescentes; outras que abordam a educação como um todo e algumas etapas ficávamos como ouvintes, conforme necessidade e vontade dos adolescentes, que em sua grande maioria gostavam de relatar suas vivências, seus questionamentos e angústias.

$\mathrm{Na}$ maioria das etapas foram realizadas oficinas temáticas semanais, debates, exposições e a elaboração de um livro, que estimularam a plena participação destes adolescentes, dinâmicas de grupo, mostra de vídeos e documentários, explicações dos temas de forma lúdica, e sempre no final, eram solicitados a dar sugestões dos temas que gostariam de esclarecer/saber um pouco mais na semana seguinte.

Todos os dados foram registrados em diários de campo e discutidos em grupo pela equipe de pesquisadores. As atividades deste projeto foram desenvolvidas por uma equipe multidisciplinar na unidade de internação feminina e também na masculina, uma vez por semana. Participavam, em média, 12 a 19 adolescentes entre doze e dezenove anos.

\section{PROBLEMATIZAÇÃO, DISCUSSÃO E ANÁLISE}

Visto que o projeto se dividia em duas unidades de medidas socioeducativas, que têm em sua estrutura adolescentes que estão em cumprimento de medidas provisória ( aguardando o tempo que irá cumprir medida) e uma outra parte já estava em cumprimento de internação( já em cumprimento do tempo estabelecido, segundo ato infracional cometido), e as diferenças entre unidade masculina e feminina. (EJLA - Escola João Luiz Alves - Unidade de Internação Masculina) e o (Centro de Socioeducação Dom Bosco - Unidade de Internação Feminina). A equipe conseguia observar como todos esses fatores influenciavam, ora de forma positiva, ora de forma negativa, no comportamento e desenvoltura dos adolescentes nas atividades.

Em se tratando de gênero, visto que a dinâmica das meninas se diferenciava dos meninos, pois o nosso contato com as mesmas se dava logo em nossa chegada, até por ser um número menor em relação a unidade masculina, todas nos recebiam alegres ( dependendo da semana,e as questões conflituosas que cada uma trazia),porém sempre na expectativa de serem ouvidas e de ouvirem as atividades propostas. Os meninos, por conta de a quantidade ser significativamente maior à unidade feminina, ficavam em seus alojamentos até nossa chegada,aguardavam a entrega da relação dos nomes e a disponibilidade de cada um ( pois em algumas vezes estavam em outras atividades) na maioria das vezes eram receptivos,porém se sentiam oprimidos e revoltados (assim se colocavam) quando algum agente chamava sua atenção.

A interação se dava de maneira oposta com a das meninas, eles no primeiro momento ficavam mais introspectivos, eram bastante observadores, porém passados primeiros minutos, já ficavam mais participativos e dispostos a colaborar com qualquer atividade, proposta. Era sempre muito positivo e 
satisfatório trabalhar com ambas as unidades que traziam em sua diferença institucional a semelhança que unia a todos: a adolescência e seus conflitos!

No que diz respeito às diferenças sobre internação e o grupo da provisória era bem nítido! O grupo que chegava recentemente (grupo da provisória) era visto pelos adolescentes como "diferentes", "estranhos no ninho", havia toda uma expectativa sobre quem era aquele novo integrante e, infelizmente, a realidade das "facções" se fazem presentes em ambas as unidades e não diferente das ruas, os adolescentes tinham uma "disputa de território velada", os grupos já formados na internação, se uniam ,como uma espécie de barreira, proteção (assim como todo o adolescente que gosta de ter seu grupo,sua turma,ali dentro não seria diferente) e todos esses grupos se mostravam para nós dentro dessa realidade, mas era sempre uma surpresa! Ora, às vezes os novos grupos interagiam bem, ficavam confiantes em ter contato conosco, ora se mantinham nos primeiros contatos desconfiados e quietos, e isso acontecia também com o grupo da internação. Rotina era uma que palavra que a equipe do PROJOVEM não conheceu na unidade de medida socioeducativa!

Participaram da primeira etapa do projeto 29 adolescentes entre 14 e 19 anos incompletos, adolescentes que cumprem medida socioeducativa na Escola João Luiz Alves e no Centro de Socioeducação Dom Bosco uma média de 21 adolescentes em ter 12 e 19 anos. É importante salientar que os temas abordados foram indicados pelos adolescentes de acordo com seus interesses.

O primeiro tema abordado foi "Doenças sexualmente transmissíveis" através de uma dinâmica de grupo, exposição e descrição das mais recorrentes doenças sexualmente transmissíveis. Este encontro contou com a presença de 14 adolescentes, os quais tiveram algumas dúvidas sobre os métodos contraceptivos, gravidez e também prevenção e tratamento destas doenças. Levamos algumas imagens das doenças e todos ficaram impressionados com as fotos e reforçamos o uso da camisinha, único método que realmente eficiente para a prevenção das doenças sexualmente transmissíveis e possui comprovadamente uma porcentagem elevada e comprovada de segurança para evitar a gravidez.

O tema seguinte "Drogas e seus efeitos" foi apresentado a um grupo de 6 adolescentes através de um jogo de encaixar ,as definições, os conceito e efeitos das drogas que foram dividias em três grupos (Drogas depressoras, estimulantes e perturbadoras). Os adolescentes se mostraram interessados; apresentaram dúvidas sobre os efeitos e conceitos. Contudo, o conteúdo exposto pela equipe-esclareceu algumas questões. Muito se foi perguntado sobre os diversos efeitos similares de drogas diferentes (que pertencem ao mesmo grupo). Alguns adolescentes negaram o uso de drogas, outros desconheciam a existência de algumas drogas. Alguns desconheciam também, que nicotina e álcool são considerados drogas. As mais conhecidas entre eles eram maconha e seu efeitos, o lança perfume e a cocaína. Assim também falamos dos vícios,e sobre drogas lícitas e drogas ilícitas. 
O terceiro tema "Urgência e emergência" foi abordado também através de um jogo, o qual a partir de uma situação exposta pela equipe os adolescentes indicariam se era caso de emergência ou urgência. Ao apresentar os dois conceitos (Emergência e Urgência) uma pequena parcela do grupo de 14 adolescentes achou que nada além da nomenclatura diferenciava estes dois conceitos. Porém, com o desenvolvimento da atividade, a maior parte afirmou que urgência seria algo rápido, neste conceito não fizeram associação com a saúde e sim com a vida cotidiana e seus problemas sociais. Já conceito de emergência foi relacionado às ações hospitalares. Dessa forma alguns colocavam algumas situações vividas em seu cotidiano e citaram as precárias condições dos hospitais públicos aos quais freqüentavam.

O quarto e último tema abordado na primeira etapa deste projeto foi "Saúde conforme o ECA", o qual contou com uma dinâmica de grupo que sinalizava se os direitos relativos à saúde estavam sendo cumpridos, esclarecia os direitos e deveres destes adolescentes, além de estimular a conscientização destes adolescentes sobre seu corpo. Diante deste encontro os adolescentes indicaram algumas mudanças, as quais representariam as condições que eles acreditam que seriam ideais e seus anseios no âmbito da saúde.

Iniciando a segunda etapa do projeto, foi realizado um encontro com o tema "Ato infracional e medida socioeducativa: por quê e pra quê?", onde se discutiu os motivos de se cometer o ato infracional, todas as pessoas envolvidas neste ato (vítima e adolescente) e a eficiência e eficácia das medidas socioeducativas. O encontro com 13 adolescentes indicou que na maioria dos casos a motivação maior é a falta de condição econômica que leva os adolescentes a cometerem estes atos e que o sistema socioeducativo ainda é muito precário no que se diz respeito à ressocialização destes adolescentes. Neste encontro levamos o ECA para que eles "folheassem" e comentarão algumas modificações que poderia ser realizada.

Citar também o convite que recebemos de participar do encontro multiprofissional na unidade do Centro de Socioeducação Dom Bosco, com a equipe de Saúde Mental e conseguir colaborar em dois casos de duas adolescentes que eram atendidas pelo PROJOVEM, expondo nossas observações, os trabalhos por elas confeccionados, a forma como participavam dos encontros e as impressões por elas deixadas,já que as adolescentes tinham com nossa a equipe uma relação de confiança e certa amizade construída a cada encontro.E esta experiência muito enriquecedora para nós participantes,foi proveitosa pois tivemos a oportunidade de ouvir cada um dos técnicos e suas observações do dia-a-dia com as adolescentes em questão,e tentar de forma indireta,trabalhar as demandas ali expostas.De uma forma geral ,todo este tempo dentro das instituições,conseguíamos uma boa parceria dos agentes,técnicos,equipe de direção e segurança para realizar as atividades com respeito e segurança,para todos os envolvidos ( a equipe e os adolescentes).Uma relação saudável, apesar de todas 
as questões envolvidas ,de modo que se em alguma semana algum membro da equipe por algum motivo tivesse que se ausentar,era sentida falta pelos adolescentes,de ambas instituições, e quando surgia feriados ou épocas de recesso, em nosso retorno,era ouvido a "reclamação" da falta sentida ,pois em ambas as unidades também era fator de indignação,a falta de mais atividades produtivas para a ocupação do tempo ocioso.

Tivemos também a oportunidade de presenciar algumas das muitas habilidades que estes jovens possuem, seja em confecção de origamis, algumas "obras" feitas com papel higiênico, sabonete, palito de sorvete, garrafas pets, jornal dentre outros materiais recicláveis, que se transformavam em barcos, buques de flores, porta-retratos, animais, corações, porta-joias dentre outros objetos... Também foram nos mostrado autoria de músicas, sejam elas em formato de funk, pagode ou música gospel, poemas e relatos em formato de diários, segundo uma adolescente, este servia como espécie de "fuga mental" para os dias mais tediosos.

Foi também vivenciado pela equipe a elaboração de alguns lutos, seja por familiares, seja pela perda da própria liberdade,seja pela saída de algum adolescente que eles ali de certa maneira se afeiçoava, fazendo a "transferência" por alguém que estava "lá fora", toda semana tinham algo novo pra contar, desabafar...

Um dos fatores motivacionais para toda equipe, era também poder falar de nossa formação (sendo equipe multiprofissional) falávamos, dos desafios, das dificuldades, das vezes que pensamos em desistir e das nossas expectativas, sobre como é importante estudar e vislumbrar o "fazer o que gosta" em sua área de atuação.

Ouvimos o despertar de sonhos, alguns já com suas sementinhas plantadas já algum tempo e outros despertando o interesse em uma possível formação, ouvimos alguns "prometer" que voltariam para a escola, que também era um sonho de sua mãe, ou de algum outro familiar, outros não aprenderam a ler, nem escrever, e sentiam vergonha por isso, tínhamos certo cuidado para que estes adolescentes não se sentissem constrangidos, nem envergonhados e conseguíamos ajudá-los quando necessário.

\section{CONSIDERAÇÕES FINAIS}

Podemos afirmar que por meio desse tipo de ação as adolescentes ampliam seu repertório interativo, melhorando sua capacidade de interferir de forma ativa, consciente e construtiva em sua realidade. Persiste, no entanto, o desafio de dar continuidade à proposta de promoção de saúde, protagonizada a partir da vivência destas adolescentes.

Contudo podemos afirmar que as ações do PROJOVEM possibilitou aos adolescentes o acesso à informação, o esclarecimento de algumas dúvidas sobre saúde e direitos humanos, além de estabelecer uma estreita relação destes com a equipe, o que por sua vez facilita o desenvolvimento das 
atividades

propostas.

Com isto o PROJOVEM contribuiu também para o amadurecimento da concepção de saúde e direitos e deveres de alguns jovens que participaram dos encontros. Por meio desse tipo de ação, os adolescentes adquirem e ampliam seu repertório interativo, aumentando assim sua capacidade de interferir de forma ativa, consciente e construtiva em sua realidade.

Há, portanto, uma necessidade de dar continuidade a discussão sobre a saúde e educação dentro da realidade destes adolescentes, entendendo que os encontros semanais através de oficinas temáticas não esgotaram as inquietações sobre tal tema, muito pelo contrário,despertou neles uma aguçada vontade de interagir e conhecer mais! Com base nos relatos dos adolescentes verificou-se também a necessidade de aprofundar questões relacionadas aos direitos e deveres destes.

Onde sabemos que a muito a ser feito, visto e revisto, porém sabemos a importância e o dever de cada um sobre o que se diz da adolescência de uma forma geral, porém dando ênfase as questões relacionadas ao adolescente em conflito com a lei,levando em consideração sua trajetória de vida,e tratando de forma sempre respeitosa,tentando dar a este adolescente a oportunidade de opinar , o PROJOVEM vem para de alguma forma ajudar o adolescente a pensar em mudar seus hábitos e atitudes, levando-os assim a fazerem escolhas mais saudáveis, tendo uma maior competência e segurança na auto-gestão de suas vidas. 


\section{REFERÊNCIAS}

ESTATUTO DA CRIANÇA E DO ADOLESCENTE, 1990, Diário Oficial da União. Lei n8069, de 13 de julho de 1990, Brasília, DF

OLIVEIRA, 1995, F. A questão do Estado: vulnerabilidade social e carência de direitos. In: Subsídios à Conferência Nacional de Assistência Social, 1. Brasília: CNAS, out. 1995. (Cadernos ABONG) 